Military Technical College

Kobry El-Kobbah, Cairo, Egypt

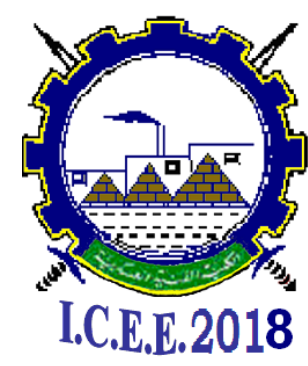

$9^{\text {th }}$ International Conference on

Chemical \& Environmental

Engineering

3-5 April 2018

\title{
SAN-3
}

\section{K-M Reactor, New Technology for Core shell Materials}

\author{
By \\ M. A. AbdelKawy ${ }^{1}$, A. El-Shazly ${ }^{2}$
}

\begin{abstract}
In this study, Nano iron-copper core shell was produced by using K-M Micro Mixer. The reaction between nano pure iron with copper sulphate pentahydrate $\left(\mathrm{CuSO}_{4} .5 \mathrm{H}_{2} \mathrm{O}\right)$ beside ethylene diamine tetraacetic acid (EDTA) as stabilizer and ascorbic acid in K-M micro mixer reactor gives many advantages in comparison with traditional chemical method for production of nano iron-Copper core shell in batch reactor. Many factors were investigated for its effect on the process performance such as initial concentrations of nano iron, copper sulphate pentahydrate, EDTA and solution flow rate. Different techniques were used for investigation and characterization of the produced nano iron particles such as SEM, XRD, UV-Vis, XPS, TEM and PSD. The produced Nano iron-copper core shell particle using micro mixer showed better characteristics than those produced using batch reactor in different aspects such as homogeneity of the produced particles, particle size distribution and size, as core diameter $10 \mathrm{~nm}$ particle size were obtained. The results showed that $10 \mathrm{~nm}$ core diameter were obtained using Micro mixer as compared to $80 \mathrm{~nm}$ core diameter in one fourth the time required by using traditional batch reactor and high thickness of copper shell and good stability.
\end{abstract}

\section{References}

[1] H.Nagasawa, N. Aoki, K.Mae, Chemical Engineering Technology, 28, p. 324-330, (2005). [2] M.Allabaksh, B.Mandal, M.Kesaral, et al, , Journal of Chemical and Pharmaceutical Research, 2(5), p.67-74 (2010).

[3]Y.Li,Z.Jin,T.Li,Z.Xiu, , Science of Total Environment ,Elsevier,p.260-266 (2012).

\footnotetext{
${ }^{\mathrm{T}}$ Central metallurgical research and development institute (CMRDI), Cairo, Egypt

${ }^{2}$ Chemical and Petrochemical Engineering Dept., Egypt-Japan University of Science and

Technology (E-JUST), New Borg EL Arab city, Alexandria, Egypt
} 